\title{
Financial incentives for smoking cessation in low-income smokers: study protocol for a randomized controlled trial
}

\author{
Jean-François Etter ${ }^{*}$
}

\begin{abstract}
Background: Tobacco smoking is the leading avoidable cause of death in high-income countries. The smoking-related disease burden is borne primarily by the least educated and least affluent groups. Thus, there is a need for effective smoking cessation interventions that reach to, and are effective in this group. Research suggests that modest financial incentives are not very effective in helping smokers quit. What is not known is whether large financial incentives can enhance longer-term (1 year) smoking cessation rates, outside clinical and workplace settings.
\end{abstract}

Trial design: A randomized, parallel groups, controlled trial.

Methods: Participants: Eight hundred low-income smokers in Switzerland (the less affluent third of the population, based on fiscal taxation).

Intervention: A smoking cessation program including: (a) financial incentives given during 6 months; and (b) Internet-based counseling. Financial rewards will be offered for biochemically verified smoking abstinence after 1, 2, and 3 weeks and 1, 3, and 6 months, for a maximum of 1,500 CHF (1,250 EUR, 1,500 USD) for those abstinent at all time-points. All participants, including controls, will receive Internet-based, individually-tailored, smoking cessation counseling and self-help booklets, but there will be no in-person or telephone counseling, and participants will not receive medications. The control group will not receive financial incentives.

Objective: To increase smoking cessation rates.

Outcome: Smoking abstinence after 6 and 18 months, not contradicted by biochemical tests. We will assess relapse after the end of the intervention, to test whether 6-month effects translate into sustained abstinence 12 months after the incentives are withdrawn.

Randomization: Will be done using sealed envelopes drawn by participants.

Blinding: Is not possible in this context.

Discussion: Smoking prevention policies and interventions have been least effective in the least educated, low-income groups. Combining financial incentives and Internet-based counseling is an innovative approach that, if proven acceptable and effective, could be later implemented on a large scale at a reasonable cost, decrease health disparities, and save many lives.

Trial registration: Current Controlled Trials ISRCTN04019434.

Keywords: Financial incentives, Smoking, Smoking cessation 


\section{Background}

Tobacco smoking is the leading avoidable cause of death and disease in high-income countries [1]. The smokingrelated disease burden is borne disproportionately by the least educated and least affluent people, because of the high smoking prevalence in these groups [2]. To reduce smoking-related health disparities, it is important to design effective smoking cessation programs that reach to low-income smokers. Since this group may be harder to reach with traditional information and education interventions [3,4], other approaches need to be explored. For instance, a strong body of research shows that both participation in addiction treatments and the outcome of these treatments are enhanced by financial incentives [5-8].

\section{Rationale}

Although people have incentives, both financial and health-related, to adopt healthy behaviors, they often fail to do so because these benefits are delayed or intangible. The immediate costs and delayed benefits of behavior change result in decision errors [9]. Giving financial incentives may offset these decision errors and encourage healthy behaviors [5,9]. However, this approach is seldom used, often because of moral considerations ("people should not be paid to do what they ought to do by themselves'), or due to the assumption that relapse will occur when the rewards are stopped. However, because of the high costs, both material and human, that smoking imposes on society [10], serious consideration must be given to any approach that may effectively and cost-effectively encourage smoking cessation.

In the field of the addictions, interventions using financial incentives are based on a robust theoretical and empirical literature that regards addiction as a form of conditioned behavior, and on well-established behavioral principles of reinforcement $[5,7,11]$. Research in animals and in humans shows that behavior can be shifted away from drug seeking when drug avoidance is rewarded by alternative reinforcers, if these reinforcers are presented at the right time and are sufficiently rewarding [12]. Furthermore, by promoting abstinence early in the treatment and by improving treatment adherence and retention, financial incentives enable people to take fuller advantage of the other components of clinical treatments [11]. Beside addictions, incentives have been widely used in other fields of medical research, to improve adherence to treatments and to make sure patients present for outcome testing [13].

\section{Efficacy of incentives for smoking cessation}

Two recent meta-analyses concluded that contingency management (i.e. financial incentives) is effective for smoking cessation, producing an effect size of 0.31 to
0.48 , which can be considered as a substantial effect $[5,7]$. A recent review also concluded that financial incentives are efficacious for smoking cessation in economically disadvantaged pregnant women [14]. A third meta-analysis found that financial incentives increased participation in smoking cessation programs, but had no sustained effect on smoking cessation [8]. However, the value of incentives used in most of the studies included in the latter meta-analysis may have been insufficient to produce long-term results (median 120 USD, range 10-750 USD). Furthermore, several of the studies included in these meta-analyses were not designed to produce long-term results. In order to be effective, the value of incentives should be high enough to compete with the reward from smoking and to compensate for withdrawal symptoms (craving, depression, weight gain, and so on) and for the loss of a valued activity. Research showed that in substance abusers, there is a doseresponse association between the monetary value of incentives and their effects on abstinence [7]. A recent study showed that financial incentives of up to 750 USD almost tripled smoking cessation rates after 12 months, compared with a no-incentives control group (14.7\% vs. $5.0 \%)$, even in highly educated, affluent workers at a multinational company ( $65 \%$ of them earned $>\$ 100,000$ ) [6]. Thus, large incentives are likely to be effective to elicit long-term (12 months) abstinence, even though it is not clear whether these results apply to less educated and less affluent smokers, and outside workplace settings [6].

Almost all of the published studies of financial incentives for smoking cessation were conducted in clinical or worksite settings, and most were relatively short-term and used small incentives $[5,7,8,14]$. It has not yet been tested whether financial incentives can enhance longterm smoking cessation in a population-based setting, that is, outside clinical and workplace settings. Finally, there is a risk that the effects of incentives may disappear after the incentives are stopped [8,15,16]. Our study will address this important point.

\section{Incentives: long-term effects}

Incentives are external motivators and may not create an enduring commitment to smoking abstinence. Thus, there is a risk that incentives will produce temporary compliance only, and that people will go back to unhealthy behaviors once the incentive program is over $[15,16]$. This problem is, however, not specific to financial incentives, as the effect of many therapeutic interventions will decline or disappear after the intervention is stopped [17]. Nevertheless, smoking cessation interventions must be designed to produce permanent smoking abstinence, as only permanent abstinence will reduce smoking-related morbidity and mortality. Thus, in 
addition to initially encouraging quit attempts and participation in smoking cessation programs, the reward schedule should reinforce long-term abstinence, in particular by offering the full amount of rewards only to participants who achieve at least several months of abstinence. Research shows that the relapse rate is relatively small once smokers reach 6 to 12 months of abstinence $[17,18]$. Thus, we will give the final incentive after 6 months and will conduct the final follow-up after 18 months, to assess relapse 12 months after the end of the incentives program.

\section{Cost-effectiveness of financial incentives}

In the USA, the median cost-effectiveness of 500 medical interventions was 42,000 USD per life year gained [19]. For comparison, the cost-effectiveness of smoking cessation treatments is in the range of 1,400-3,500 USD per life year gained $[20,21]$. Thus, smoking cessation treatments are about 10 to 20 times more cost-effective than the average medical treatment. In fact, together with vaccines, tobacco dependence treatments are among the most cost-effective of all medical interventions [22]. A review found that the cost-effectiveness of nicotine replacement therapy (NRT) and bupropion is about 1,000 GBP (1,600 CHF) per quitter [20,21]. In our program, financial incentives will cost up to $1,500 \mathrm{CHF}$ per quitter, but previous research shows that on average, participants receive only about $40 \%$ to $50 \%$ of the maximum reward available [16,23], that is, about 600 to $800 \mathrm{CHF}$ if the maximum reward is $1,500 \mathrm{CHF}$. This amount is substantially lower than the cost per quitter for pharmacological or medical treatments, considering that over $80 \%$ of patients treated in clinical trials fail to quit, and that incentives are paid to successful quitters only. Thus, the planned intervention is likely to be as cost-effective as other smoking cessation interventions, and substantially more cost-effective than the average medical intervention. Finally, previous research shows that financial incentives for patients in addiction treatment are costeffective [24,25].

\section{Ethics}

\section{Risks to participants}

There is no known risk associated with the Internetbased behavioral support. We think it is unlikely that many non-smokers will smoke before baseline just to test positive on cotinine and $\mathrm{CO}$, in order to be eligible for this study. Besides smoking-related variables, no health-related information will be collected. The files containing the names of participants will be kept confidential and will be accessible only to the first investigator, the computer expert in charge of managing the online data collection system and the research assistant.

\section{Migros gift cards instead of cash}

In order to make sure that the money is not spent on cigarettes, alcohol, or drugs, incentives will be paid exclusively in Migros gift cards. Migros is the largest supermarket chain in Switzerland, and does not sell alcohol or tobacco. It also sells furniture, DIY, garden and sport items, electronic equipment, and has restaurants.

\section{Informed consent, approval}

All participants will sign a consent form (on paper, not online). Participants will receive the intervention at no charge. The study was approved by the ethics committee of the Geneva University Hospitals and is registered in Current Controlled Trials (ISRCTN04019434).

\section{Methods/design \\ Objectives}

The objective is to test whether a smoking cessation program combining financial incentives with Internetbased, individually-tailored behavioral support improves smoking cessation rates in low-income smokers, compared with cessation rates observed in a no-incentives control group, and to measure the size of this effect, 12 months after the incentives are stopped, that is, 18 months after the intervention starts. The secondary objectives are: to study whether the outcome is influenced by the characteristics of participants: age, sex and education, tobacco dependence level, motivation to quit (intrinsic/extrinsic [26]), and smoking history; to assess the effect of financial incentives on quit attempts; and to assess whether financial incentives improve use of the online smoking cessation program.

\section{Design of the trial}

A two-arm, open-label, randomized controlled trial with follow-up after 3, 6, and 18 months. We will compare an intervention group that receives financial incentives plus Internet-based support to a control group that receives Internet-based support but no incentives.

\section{Randomization}

Randomization will take place after we receive the baseline survey and consent form and after we verify eligibility. Randomization will be done with sealed envelopes drawn by participants.

\section{Allocation concealment}

Participants cannot be blinded to their assignment group. Online data collection will be automatic, and thus, there will be no bias in online assessments. In non-respondents to the online surveys, follow-up data will be collected by postal mail, and in nonrespondents to the postal questionnaires, a minimal 
set of questions (smoking status, quit date, and cigarettes/day) will be asked over the phone.

\section{Sequence and duration of follow-up}

Confirmed quitters in the intervention group will receive financial rewards six times: after 1, 2, and 3 weeks, and 1 , 3 , and 6 months. We will conduct questionnaire surveys and measure saliva cotinine and expired carbon monoxide (CO) levels in both study groups at baseline and after 3 and 6 months (end of the intervention), and after 18 months (that is, 12 months after the end of the intervention, to assess post-intervention relapse) (Figure 1).

\section{Timetable and project duration}

The preparation phase will last 9 months, the enrolment phase 18 months, the observation phase 18 months, and the data analysis 3 months. Thus, the total duration of the study is 4 years.

\section{Data}

\section{Questionnaires}

The questionnaires will be collected online, and for nonrespondents to the online surveys, by postal mail and over the phone. The questionnaires will be brief and focused, in order to maximize participation. Four waves of questionnaires will be collected in both study groups: at baseline and after 3, 6, and 18 months.

The baseline questionnaire will cover:

- Age and sex, school years, occupation, income, body weight and height.

- Smoking status, cigarette consumption, level of tobacco dependence.

- Motivation to quit (intrinsic/extrinsic) [26], past quit attempts, planned quit date.
- Current and past use of smoking cessation treatments and medications.

- Address, phone number, e-mail, Internet access.

The follow-up questionnaires (after 3, 6, and 18 months) will cover:

- Smoking status (any smoking in the past 7 days, 4 weeks, 6 and 12 months).

- Quit date in ex-smokers.

- In current smokers: cigarette consumption and level of dependence.

- Quit attempts (number, duration, dates).

- Motivation to quit (intrinsic/extrinsic), confidence in ability to quit.

- Smoking cessation treatments used since enrolment.

- Opinions, satisfaction with the intervention.

- Items bought with the gift cards by quitters in the intervention group.

- Body weight.

Participants will automatically receive an e-mail message inviting them to take part in the online follow-up surveys, 3,6 , and 18 months after their target quit date. Participants who report that they have not smoked any tobacco in the past 7 days will be invited to make an appointment within the next days for biochemical verification.

\section{Cotinine, $\mathrm{CO}$, and thiocyanate measurements}

Biochemical verification is essential in financial incentives programs. Cotinine and $\mathrm{CO}$ tests will be conducted at baseline in all participants (to verify that they are smokers), and at each follow-up (3, 6, and 18 months), in both study groups (intervention and control), only in participants who declare that they have not smoked even a puff

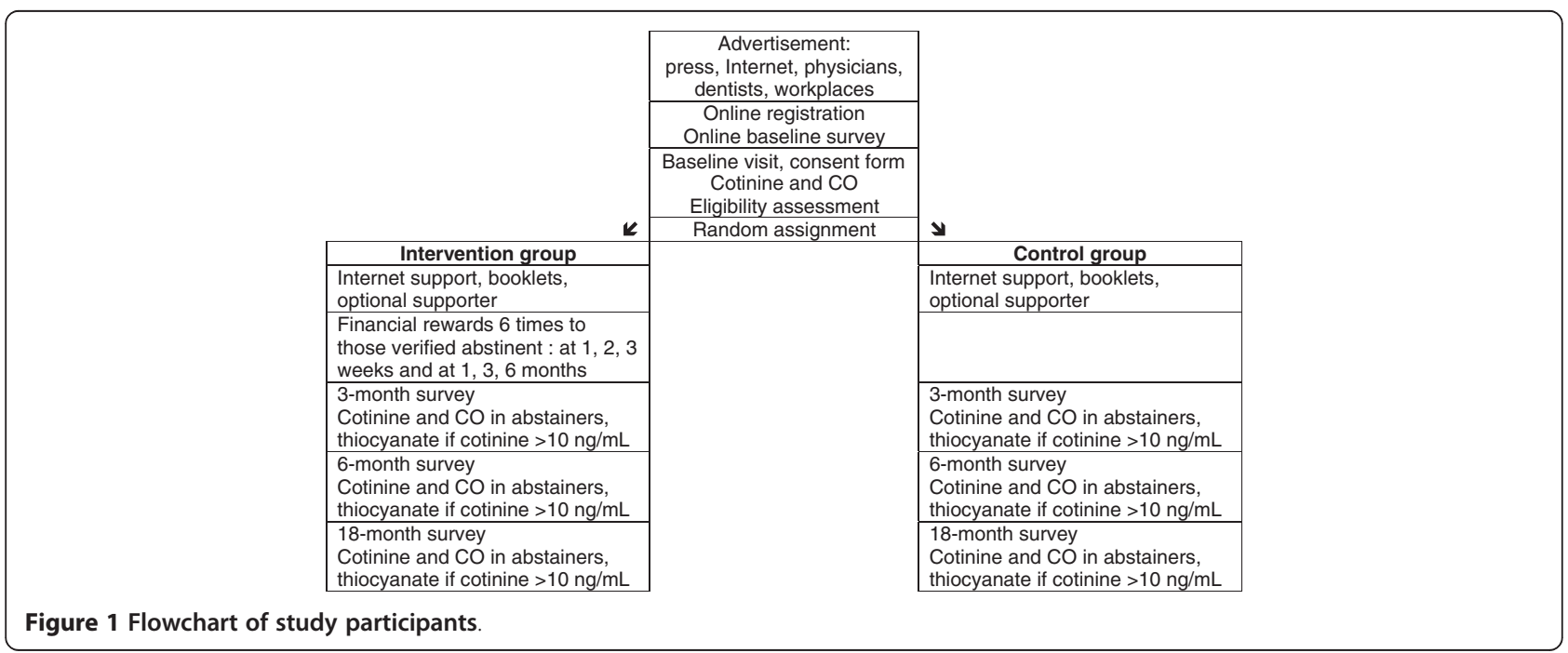


of tobacco in the previous 7 days. Self-reported quitters will come to our center to provide $\mathrm{CO}$ and saliva. $\mathrm{CO}$ tests will be performed with a Bedfont Micro Smokerlyzer, and cotinine in saliva will be assessed with NicAlert tests strips, that can detect cotinine levels $>10 \mathrm{ng} / \mathrm{mL}$ [27]. Compared with gas chromatography, NicAlert tests strips have a specificity of $95-96 \%$, a sensitivity of $93-99 \%$, a positive predictive value of $95 \%$, and a negative predictive value of $93 \%$ $[27,28]$. In self-reported non-smokers who report using NRT at follow-up and have a negative CO test (0-3 ppm) but a positive cotinine test (NicAlert level $>=1$, that is, $>10 \mathrm{ng} / \mathrm{mL}$ ) [29,30], we will use thiocyanate to verify smoking abstinence (cutoff: $100 \mu \mathrm{mol} / \mathrm{L}$ ) [31,32]. For thiocyanate analysis, saliva samples will be collected in a plastic vial (salivette, Sarstedt) and frozen until sent to the laboratory. Tobacco alkaloids (anabasine or anatabine) are more specific than thiocyanate. However, analyses of anatabine or anabasine are expensive and are not routinely conducted in saliva. In this community setting, taking blood or urine samples will not be feasible.

\section{Procedure (see flowchart)}

To improve participation in biochemical tests, participants in both study groups will be compensated (Migros gift card, value $25 \mathrm{CHF}$ ) for providing saliva and $\mathrm{CO}$ samples at follow-up (not at baseline and not when another incentive is given on the same visit). There will be a 6-day time window for the biochemical verification for the first three assessments (that is, after 1, 2, and 3 weeks): people will have to provide the biochemical samples within 6 days of each assessment point. The time window will be 1 month for the 1 and 3 months assessments and 3 months for the
6 and 18 months assessments. These windows were set to maximize participation, because in a community setting, as opposed to workplace or clinical settings, all participants may not strictly keep appointments.

$\mathrm{CO}$ and cotinine tests will be conducted in selfreported quitters only. Those with negative $\mathrm{CO}$ tests $(0-3 \mathrm{ppm})$ and negative NicAlert tests (level $=0$, that is $<10 \mathrm{ng} / \mathrm{mL}$ ) will be declared quitters and will receive their reward immediately, during the same clinic visit. Those who have positive $\mathrm{CO}$ tests $(>=4 \mathrm{ppm})$ will be declared smokers. Those with negative CO tests $(0-3 \mathrm{ppm})$ but positive NicAlert tests (level $>=1$ ) will be asked whether they are sure they actually quit. Those who answer 'yes' and who currently use NRT will provide a saliva sample for thiocyanate analysis. Those with negative thiocyanate results will be considered quitters (Figure 2). Using CO, cotinine, and thiocyanate allows for a more stringent test of abstinence than in most previous studies of incentives, which used only $\mathrm{CO}$. Carbon monoxide reflects tobacco use during the last few hours, and cotinine and thiocyanate during the last few days only. No biochemical test allows for the verification of abstinence over more than a few days.

\section{Selection and withdrawal of subjects Enrolment strategies}

Participants will be 800 low-income smokers. They will be informed of the study via advertisements in the press, on the Internet, in workplaces, hospitals, pharmacies, clinics and medical and dentistry offices, by direct mailing, and by direct contact with the study assistant in the streets and at sports events. Advertisements will be

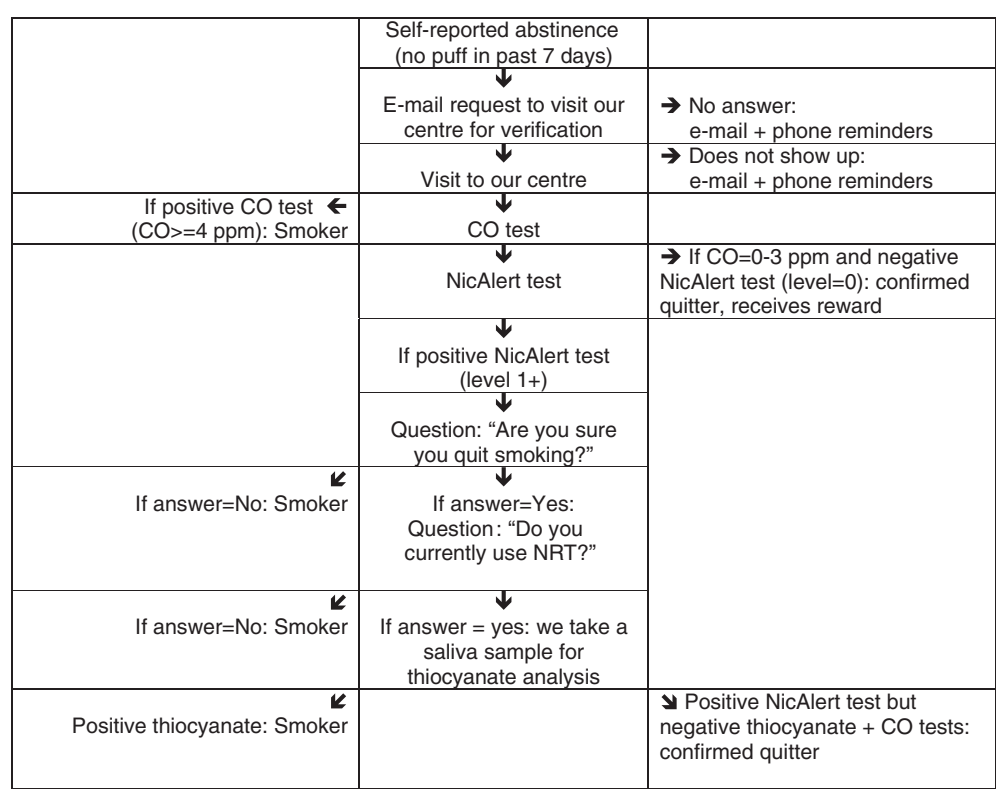

Figure 2 Flowchart for the verification of smoking abstinence. 
placed in media and in events that reach to low income, low educated people (for example football and hockey games, free newspapers). The advertisements will inform participants of the possibility of earning up to 1,500 CHF for participating in a smoking cessation study. After answering the online baseline questionnaire, participants will visit our center, where eligibility will be assessed. We define 'low income' as a documented taxable annual household income $\leq 50,000$ CHF for single people and $<=100,000$ CHF for married people, which is the income of roughly the least affluent third of households in Geneva [33].

\section{Subject inclusion criteria}

1. $>18$ years old.

2. Taxable income $\leq 50,000 \mathrm{CHF}$ (single) or $<=100,000$ $\mathrm{CHF}$ (married), proven by most recent fiscal taxation.

3. Smokes at least five cigarettes per day, every day.

4. Has smoked for at least 1 year.

5. Baseline CO reading of at least $10 \mathrm{ppm}$.

6. Baseline saliva cotinine reading of NicAlert level 1 or higher $(>=10 \mathrm{ng} / \mathrm{mL})$.

7. Sets a quit date within 1 month and commits to quit at that date by signing the quitter contract.

8. Commits to take part in all follow-up surveys and in all biochemical tests.

9. Declares to understand and to accept the control group procedure.

10. Signs informed consent form at each line.

11. Shows identity document with photo (a copy will be kept in our records).

12. Has regular access to Internet and e-mail.

13. Commits to read e-mail daily during the study.

14. Valid e-mail address, postal address and telephone number.

\section{Subject exclusion criteria}

- Not meeting all 14 inclusion criteria

In Switzerland, $80 \%$ of the general population had Internet access in 2010, including $70 \%$ of low-income people and $92 \%$ of low-income people younger than 35 years [34]. Thus, requiring regular Internet access may result in a selected subsample of low-income people, but only in those older than 35 years, since in younger people, almost everyone has Internet access.

\section{The intervention}

Tests of financial incentives have almost always been conducted in association with clinical treatment, rather than as stand-alone treatments $[7,8]$. Thus, in addition to financial rewards, all participants will receive behavioral support. The intervention will have five components:

1 Component for the intervention group only:

1. Financial incentives of up to $1500 \mathrm{CHF}$, paid to those verified abstinent.

\section{Components for both the intervention and the control groups:}

2. Internet-based smoking cessation program.

3. Self-help booklets.

4. Optional enrolment of a social supporter of their choice.

5. Quitter contract with quit date (signed by participant, supporter, and study assistant).

Thus, the study will test the effect of financial incentives, over and above a psychosocial intervention comprised of an online program, booklets, a social supporter (optional), and a quitter contract. This is a realistic intervention requiring no medical staff (no physician, nurse, or psychologist). There will be no in-person or telephone counseling, and participants will not receive medication. Thus, if proven effective, this intervention will be implementable at a large scale with reasonable resources.

\section{Financial incentives}

Value of rewards In substance abusers, greater monetary values of incentives are associated with larger effects on abstinence [7], and small rewards to not produce sustained effects on smoking cessation [8]. Furthermore, the only study that found a sustained (12-18 months) effect of incentives on smoking cessation used large incentives, of up to 750 USD (which corresponded to $950 \mathrm{CHF}$ in 2005 values, when this study was conducted) [6]. In an opinion survey in the US, when asked how much money should be paid to smokers to quit smoking, 53\% of participants responded 0 USD, 36\% responded 50-500 USD and $11 \%$ responded $>1,000$ USD [35]. When we asked the same question to 120 visitors of the Stop-tabac website, $26 \%$ responded $0 \mathrm{CHF}$, $22 \%$ responded $10-500 \mathrm{CHF}$, and 53\% responded $>1,000 \mathrm{CHF}$. Based on this information, we will use incentives of up to $1,500 \mathrm{CHF}$. However, previous research shows that on average, participants in incentive programs receive only about $40-50 \%$ of the maximum reward available [16,23], that is, about 600-800 CHF if the maximal amount available is $1,500 \mathrm{CHF}$. A reward of $1,500 \mathrm{CHF}$ corresponds to $36 \%$ of the monthly income of people who earn 50,000 CHF per year. For reasons stated above, incentives will be paid in Migros gift cards, not in cash. 
Frequency of rewards Because relapse occurs rapidly after a quit attempt is initiated, abstinence needs to be reinforced early on [36]. Research shows that incentives have a larger impact if they are delivered at high frequency, soon after the target behavior takes place [11]. Thus, participants will be instructed to present at our center for verification as soon as they achieve 1 week of abstinence, so that abstinence can be reinforced soon after it occurs. Abstinence will be reinforced weekly during the first month, and then after 3 and 6 months.

Immediacy of rewards Research shows that reinforcement works best when the target behavior is followed by the reinforcer without delay [37]. Delayed rewards are discounted, and a smaller amount given now is valued the same as a larger amount given later. In substance abusers, rewards are about twice as effective when they are delivered immediately, during the same clinic visit, than when the payment is delayed [7]. Thus, we will pay rewards immediately after conducting the cotinine and $\mathrm{CO}$ tests, during visits at our center. This is why we will use NicAlert tests strips that produce results within a few minutes [27].

Escalation and reset Research shows that escalating systems produce longer periods of smoking abstinence compared with constant rewards [38]. Because we want to reward sustained abstinence rather than initial quit attempts, we will use an escalating scheme and give incentives six times during 6 months (100, 150, 200, 300, 350, and $400 \mathrm{CHF}$ at 1, 2, 3 weeks and at 1, 3, and 6 months, respectively). If people smoke or miss an assessment, the value of the next reward will be reset to the value of the last reward they attained, and the escalation scheme will start again at this value. Incentives will be paid only to people with negative $\mathrm{CO}$ and cotinine in saliva, assessed with NicAlert tests strips, and to NRT users who have positive cotinine tests but negative $\mathrm{CO}$ tests [27].

\section{Behavioral intervention for both study groups Quitter contract with quit date}

A contract will be signed by each study participant, and countersigned by the research assistant and by the optional social supporter. In this contract, participants will commit to quit at a target quit date set no later than 1 month after enrolment, and to make additional quit attempts at a later date if the first quit attempt fails.

\section{Social supporter}

Participants who agree will designate a social supporter, preferably a non-smoker, with whom they have a regular, positive association (for example, spouse, friend, or colleague). Social supporters will countersign the participant's quit contract. Social supporters will sign a consent form, receive a document describing their role in the study, and answer a brief questionnaire to return to us by mail, about their smoking status, age, sex, and address.

\section{Internet-based, automatic behavioral support ('Coach')}

Participants in both study groups will have the opportunity to enrol in an online 'Coach', which is an automatic, interactive, smoking cessation program. The 'Coach' consists of individually-tailored feedback reports, personal pages with progress graphs and a series of e-mail messages sent automatically over 3 months [3,39]. Participants will also be encouraged to use the other services available on the Stop-tabac.ch website (discussion forums, 'chats', testimonials, fact sheets, and so on).

There will be no in-person behavioral support of telephone support. However, participants will be able to call the study assistant for administrative purposes.

\section{Booklets}

Participants in both the intervention and the control group will receive a series of self-help booklets [3,40]. Finally, we will inform participants if any new, effective treatment of tobacco dependence is discovered during the study.

\section{Control group procedures}

After randomization, participants in the control group will be informed about their group assignment, during the enrolment visit. They will be advised to quit smoking and will be encouraged to use the Stop-tabac website and self-help booklets in the same manner as the intervention group. They will be contacted again only for the followup surveys and for the cotinine, $\mathrm{CO}$, and thiocyanate tests after 3, 6, and 18 months. In follow-up surveys, we will ask participants in both study groups whether they obtained smoking cessation support, and the type and amount of support they obtained (Internet, quitline, smoking cessation clinic, physician, medications, and so on). In data analyses, this will enable us to control for the amount of support received by participants.

\section{Cessation induction vs. aid to cessation}

Financial incentives may have two types of effects: they may induce quit attempts in people who would not otherwise have tried to quit (cessation induction); and they may increase the success of quit attempts (aid to cessation) [41]. Since all participants will commit to make a quit attempt and set a quit date within 1 month of enrolment, our trial will not be a good test of cessation induction, it will rather be an aid-to-cessation trial. We will nevertheless assess the effect of the intervention on quit attempts, as a secondary outcome. 


\section{Assessment of efficacy}

The primary outcome will be continuous smoking abstinence between 6 and 18 months, that is, self-report of no puff of tobacco in the previous 7 days at 6 months plus self-report of no smoking between the 6- and 18month surveys, not contradicted by $\mathrm{CO}$, cotinine, and thiocyanate measurements. The date for follow-up surveys will be tied to the target quit date set at baseline.

As secondary outcomes, we will also assess:

- Biochemically confirmed point prevalence of abstinence after 3, 6 and 18 months.

- Abstinence at 3, 6, and 18 months using the 'Russell Standard', a recently suggested standard for smoking cessation trials [42].

- Quit attempts during the intervention phase (number, duration and dates).

- Cigarette consumption, motivation to quit, confidence in ability to quit.

- Use of the online smoking cessation program.

Methods for assessing and recording efficacy parameters To avoid using paper, questionnaires will be collected online. In non-respondents to the online surveys only, questionnaires will be collected by postal mail and then by phone.

\section{Baseline data}

After answering the online baseline questionnaire, participants will visit our center in Geneva, where smoking status will be biochemically verified. No smoking cessation counseling will be provided during the enrolment visit.

\section{Follow-up after 3, 6, and 18 months}

Participants will automatically receive by e-mail a request to answer the online follow-up questionnaires, 3, 6, and 18 months after their target quit date. After six e-mail reminders sent every 3 days, non-respondents to the online surveys will receive the follow-up questionnaires by postal mail. After three reminders by postal mail, nonrespondents will be contacted by phone [43]. The telephone survey in non-respondents will cover only a minimal subset of questions (smoking status, quit attempts, quit date and cigarettes/day). After six unsuccessful tries to reach non-respondents by phone at different hours and days of the week, we will contact a next of kin or a friend (whose address was provided at baseline by participants who agree with this procedure) to locate non-respondents. In our previous trials, this procedure enabled us to obtain response rates of about 95\% [40,44].

There is a risk that participants in the control group will drop out of the study when they learn about their group allocation, which would represent a threat to the validity of the study. We will make sure we obtain similarly high response rates in both study groups at follow-up.

\section{Biochemical verification}

The outcome is self-reported prolonged abstinence that is not contradicted by biochemical tests of recent abstinence. After 3, 6, and 18 months, participants who report abstinence (no puff of tobacco in the previous 7 days) will be invited to come to our center to perform a $\mathrm{CO}$ test and provide saliva samples for cotinine analysis and, if necessary, thiocyanate analysis. The procedure described above (multiple reminders by e-mail, postal mail, and telephone) will also be used to invite participants for the biochemical tests. After the reminders, a study assistant will offer to smokers who claim abstinence but do not show up for testing to meet them at their home or workplace or at a public space, to collect the $\mathrm{CO}$ and saliva samples. The saliva samples will be destroyed after the cotinine and thiocyanate analyses.

\section{Statistics}

The main analysis will be a comparison of the proportions of abstinent smokers in the intervention and control groups. We will use chi-square tests and odds ratios with 95\% confidence intervals to compare these proportions. If covariates are needed due to imbalance despite randomization, we will use multivariate logistic regression models instead. We will conduct subgroups analyses, and will use multivariate models to test whether the outcome is influenced by participants' characteristics. We will assess whether motivation (intrinsic or extrinsic) acts as a mediator in the association between incentives and behavior [26]. Analyses will compare participants who did or did not have a social supporter, or who did or did not use the online Coach, to see if these influence outcome or interact with treatment assignment.

\section{Sample size calculation}

Based on our previous research in a similar population, we expect a quit rate of about $10 \%$ in the control group $[39,45]$. Previous research showed that financial incentives either have little long-term effect on smoking cessation [8], or an effect size of 0.31 to 0.48 [5,7], but larger incentives have a substantial effect (odds ratio $>3$ ) [6]. A sample size of 800 participants $(2 \times 400)$ will enable us to detect a difference between quit rates of $10 \%$ in the control group and $17 \%$ in the intervention group (odds ratio $=1.84$, power $=80 \%, P=0.05$ ).

\section{Intention-to-treat, missing data}

For the primary outcome, participants will be evaluated in an intention-to-treat analysis, with all randomized participants in the denominator. Participants with missing data at follow-up will be counted as smokers. We will 
also conduct sensitivity analyses with different assumptions for missing data. Based on our previous studies, we expect $5 \%$ of missing data $[46,47]$.

\section{Discussion}

Combining financial incentives with Internet-based behavioral support is an innovative approach, feasible, easily disseminated, and potentially cost-effective. This study will help us understand whether financial incentives and the Internet can be used to modify health-related behaviors in a population-based setting, and it will provide valuable information on the categories of people in whom this intervention is most effective and on the acceptability of this intervention. This program is of particular interest for low-income populations, in whom smoking prevalence is particularly high. If this study proved that this intervention is effective, this would suggest that, to reduce disparities in smoking due to income and education, tobacco control programs may shift prevention budgets from education and information campaigns to a structured program combining financial incentives with online behavioral support. Therefore, this study has the potential to influence policy decisions. If this program was proven effective, it could be widely disseminated, have a substantial impact on smoking cessation rates, decrease health disparities and save many lives.

\section{Trial status}

The enrolment of participants started in August 2011 and will last until February 2013.

\section{Abbreviations \\ CO: Carbon monoxide; DIY: Do it yourself; NRT: Nicotine replacement therapy.}

\section{Competing interests}

The authors declare that they have no competing interests.

\section{Authors' contributions}

J-FE had the idea for the study, wrote the study protocol and this article, obtained funding for the study, and is in charge of the implementation of the trial.

\section{Author's information}

Jean-François Etter is the author of over 100 publications in peer-reviewed journals, most of them on smoking cessation, and is assistant editor of two of the leading journals in the field: Addiction and Nicotine \& Tobacco Research. He has an extensive experience in conducting randomized trials and in developing and implementing smoking cessation interventions. The planned research is an extension and a development of his previous research.

\section{Funding}

Tobacco Prevention Fund of the Swiss Federal Office of Public Health: 676,000 CHF (560,000 EUR, 690,000 USD).

\section{Acknowledgements}

Vincent Baujard, from the Health On The Net Foundation, developed the software for data collection. The study is funded by the Tobacco Prevention Fund of the Swiss Federal Office of Public Health.
Received: 26 January 2012 Accepted: 25 May 2012

Published: 21 June 2012

\section{References}

1. Ezzati M, Lopez AD: Estimates of global mortality attributable to smoking in 2000. Lancet 2003, 362:847-852.

2. Huisman $M$, Kunst $A E$, Mackenbach JP: Inequalities in the prevalence of smoking in the European Union: comparing education and income. Prev Med 2005, 40:756-764.

3. Etter JF, Perneger TV: Effectiveness of a computer-tailored smoking cessation program: a randomized trial. Arch Intern Med 2001, 161:2596-2601.

4. Townsend J, Roderick P, Cooper J: Cigarette smoking by socioeconomic group, sex, and age: effects of price, income, and health publicity. BMJ 1994, 309:923-927.

5. Prendergast M, Podus D, Finney J, Greenwell L, Roll J: Contingency management for treatment of substance use disorders: a meta-analysis. Addiction 2006, 101:1546-1560.

6. Volpp KG, Troxel AB, Pauly MV, Glick HA, Puig A, Asch DA, Galvin R, Zhu J, Wan F, DeGuzman J, Corbett E, Weiner J, Audrain-McGovern J: A randomized, controlled trial of financial incentives for smoking cessation. N Engl J Med 2009, 360:699-709.

7. Lussier JP, Heil SH, Mongeon JA, Badger GJ, Higgins ST: A meta-analysis of voucher-based reinforcement therapy for substance use disorders. Addiction 2006, 101:192-203.

8. Cahill K, Perera R: Competitions and incentives for smoking cessation. Cochrane Database Syst Rev 2011, (4):CD004307.

9. Loewenstein G, Brennan T, Volpp KG: Asymmetric paternalism to improve health behaviors. JAMA 2007, 298:2415-2417.

10. Jeanrenaud C, Vitale S, Priez F: Le coût social de la consommation de tabac en Suisse. Neuchâtel: Institut de Recherches Economiques; 1998.

11. Petry NM: A comprehensive guide to the application of contingency management procedures in clinical settings. Drug Alcohol Depend 2000, 58:9-25.

12. Higgins ST, Petry NM: Contingency management. Incentives for sobriety. Alcohol Res Health 1999, 23:122-127.

13. Stitzer ML, Vandrey R: Contingency management: utility in the treatment of drug abuse disorders. Clin Pharmacol Ther 2008, 83:644-647.

14. Higgins ST, Washio Y, Heil SH, Solomon LJ, Gaalema DE: Higgins TM, Bernstein IM: Financial incentives for smoking cessation among pregnant and newly postpartum women. Prev Med; 2011 [Epub ahead of print].

15. Volpp KG, Levy AG, Asch DA, Berline JA, Murphy JJ, Gomez A, Sox H, Zhu J, Lerman C: A randomized controlled trial of financial incentives for smoking cessation. Cancer Epidemiol Biomarkers Prev 2006, 15:12-18.

16. Shoptaw S, Rotheram-Fuller E, Yang X, Frosch D, Nahom D, Jarvik ME, Rawson RA, Ling W: Smoking cessation in methadone maintenance. Addiction 2002, 97:1317-1328

17. Etter JF, Stapleton JA: Nicotine replacement therapy for long-term smoking cessation: a meta-analysis. Tob Control 2006, 15:280-285.

18. Hughes JR, Peters EN, Naud S: Relapse to smoking after 1 year of abstinence: a meta-analysis. Addict Behav 2008, 33:1516-1520.

19. Tengs TO, Adams ME, Pliskin JS, Safran DG, Siegel JE, Weinstein MC, Graham JD: Five-hundred life-saving interventions and their cost-effectiveness. Risk Anal 1995, 15:369-390.

20. Song F, Raftery J, Aveyard P, Hyde C, Barton P, Woolacott N: Costeffectiveness of pharmacological interventions for smoking cessation: a literature review and a decision analytic analysis. Med Decis Making 2002, Suppl 5:S26-S37.

21. Woolacott NF, Jones L, Forbes CA, Mather LC, Sowden AJ, Song FJ, Raftery JP, Aveyard PN, Hyde CJ, Barton PM: The clinical effectiveness and costeffectiveness of bupropion and nicotine replacement therapy for smoking cessation: a systematic review and economic evaluation. Health Technol Assess 2002, 6:1-245.

22. Maciosek MV, Coffield AB, Edwards NM, Flottemesch TJ, Goodman MJ, Solberg LI: Priorities among effective clinical preventive services: results of a systematic review and analysis. Am J Prev Med 2006, 31:52-61.

23. Heil SH, Higgins ST, Bernstein IM, Solomon LJ, Rogers RE, Thomas CS, Badger GJ, Lynch ME: Effects of voucher-based incentives on abstinence from cigarette smoking and fetal growth among pregnant women. Addiction 2008, 103:1009-1018. 
24. Sindelar $J \mathrm{~L}$, Olmstead TA, Peirce JM: Cost-effectiveness of prize-based contingency management in methadone maintenance treatment programs. Addiction 2007, 102:1463-1471.

25. Sindelar J, Elbel B, Petry NM: What do we get for our money? Costeffectiveness of adding contingency management. Addiction 2007 102:309-316.

26. Curry S, Wagner EH, Grothaus LC: Intrinsic and extrinsic motivation for smoking cessation. J Consult Clin Psychol 1990, 58:310-316

27. Cooke F, Bullen C, Whittaker R, McRobbie H, Chen MH, Walker N: Diagnostic accuracy of NicAlert cotinine test strips in saliva for verifying smoking status. Nicotine Tob Res 2008, 10:607-612.

28. Montalto NJ, Wells WO: Validation of self-reported smoking status using saliva cotinine: a rapid semiquantitative dipstick method. Cancer Epidemiol Biomarkers Prev 2007, 16:1858-1862.

29. Javors MA, Hatch JP, Lamb RJ: Cut-off levels for breath carbon monoxide as a marker for cigarette smoking. Addiction 2005, 100:159-167.

30. Etter JF, Vu Duc T, Perneger TV: Saliva cotinine levels in smokers and nonsmokers. Am J Epidemiol 2000, 151:251-258.

31. Haley NJ, Axelrad CM, Tilton KA: Validation of self-reported smoking behavior: biochemical analyses of cotinine and thiocyanate. Am J Public Health 1983, 73:1204-1207.

32. Vogt TM, Selvin S, Widdowson G, Hulley SB: Expired air carbon monoxide and serum thiocyanate as objective measures of cigarette exposure. Am J Public Health 1977, 67:545-549.

33. Office Cantonal de la Statistique (OCSTAT): Répartition des contribuables et du revenu annuel brut, selon la classe de revenu. Genève: OCSTAT; 2006.

34. Office Fédéral de la Statistique: Internet dans les ménages en Suisse Résultats de l'enquête Omnibus TIC 2010. Neuchâtel: Office Fédéral de la Statistique; 2012.

35. Long JA, Helweg-Larsen M, Volpp KG: Patient opinions regarding 'pay for performance for patients'. J Gen Intern Med 2008, 23:1647-1652.

36. Hughes JR, Keely J, Naud S: Shape of the relapse curve and long-term abstinence among untreated smokers. Addiction 2004, 99:29-38.

37. Rowan-Szal G, Joe GW, Chatham LR, Simpson DD: A simple reinforcement system for methadone clients in a community-based treatment program. J Subst Abuse Treat 1994, 11:217-223.

38. Roll JM, Higgins ST, Badger GJ: An experimental comparison of three different schedules of reinforcement of drug abstinence using cigarette smoking as an exemplar. J Appl Behav Anal 1996, 29:495-504.

39. Etter JF: Comparing the efficacy of two Internet-based, computer-tailored smoking cessation programs: a randomized trial. J Med Internet Res 2005, 7:e2.

40. Etter JF: Informing smokers about additives in cigarettes a randomized trial. Patient Educ Counsel 2007, 66:188-191.

41. Hughes JR, Keely JP, Niaura RS, Ossip-Klein DJ, Richmond RL, Swan GE: Measures of abstinence in clinical trials: issues and recommendations. Nicotine Tob Res 2003, 5:13-25.

42. West R, Hajek P, Stead L, Stapleton J: Outcome criteria in smoking cessation trials: proposal for a common standard. Addiction 2005, 100:299-303.

43. Dillman DA: Mail and Internet surveys: the tailored design method. New York: John Wiley \& Sons; 2000.

44. Etter JF, Cornuz J, Huguelet P, Perneger TV: Pre-cessation treatment with nicotine replacement therapy: a randomized trial. Arch Intern Med 2009, 169:11.

45. Etter JF: Comparing computer-tailored, internet-based smoking cessation counseling reports with generic, untailored reports: a randomized trial. $J$ Health Commun 2009, 14:646-657.

46. Etter JF, Huguelet P, Perneger TV, Cornuz J: Nicotine gum treatment before smoking cessation: a randomized trial. Arch Intern Med 2009, 169:1028-1034.

47. Etter JF, Laszlo E, Zellweger JP, Perrot C, Perneger TV: Nicotine replacement to reduce cigarette consumption in smokers who are unwilling to quit: a randomized trial. J Clin Psychopharmacol 2002, 22:487-495.

\section{doi:10.1186/1745-6215-13-88}

Cite this article as: Etter: Financial incentives for smoking cessation in low-income smokers: study protocol for a randomized controlled trial. Trials 2012 13:88.

\section{Submit your next manuscript to BioMed Central and take full advantage of:}

- Convenient online submission

- Thorough peer review

- No space constraints or color figure charges

- Immediate publication on acceptance

- Inclusion in PubMed, CAS, Scopus and Google Scholar

- Research which is freely available for redistribution 